\title{
Supporting Information \\ Bioactive and elastic nanocomposites with antimicrobial properties for bone tissue regeneration
}

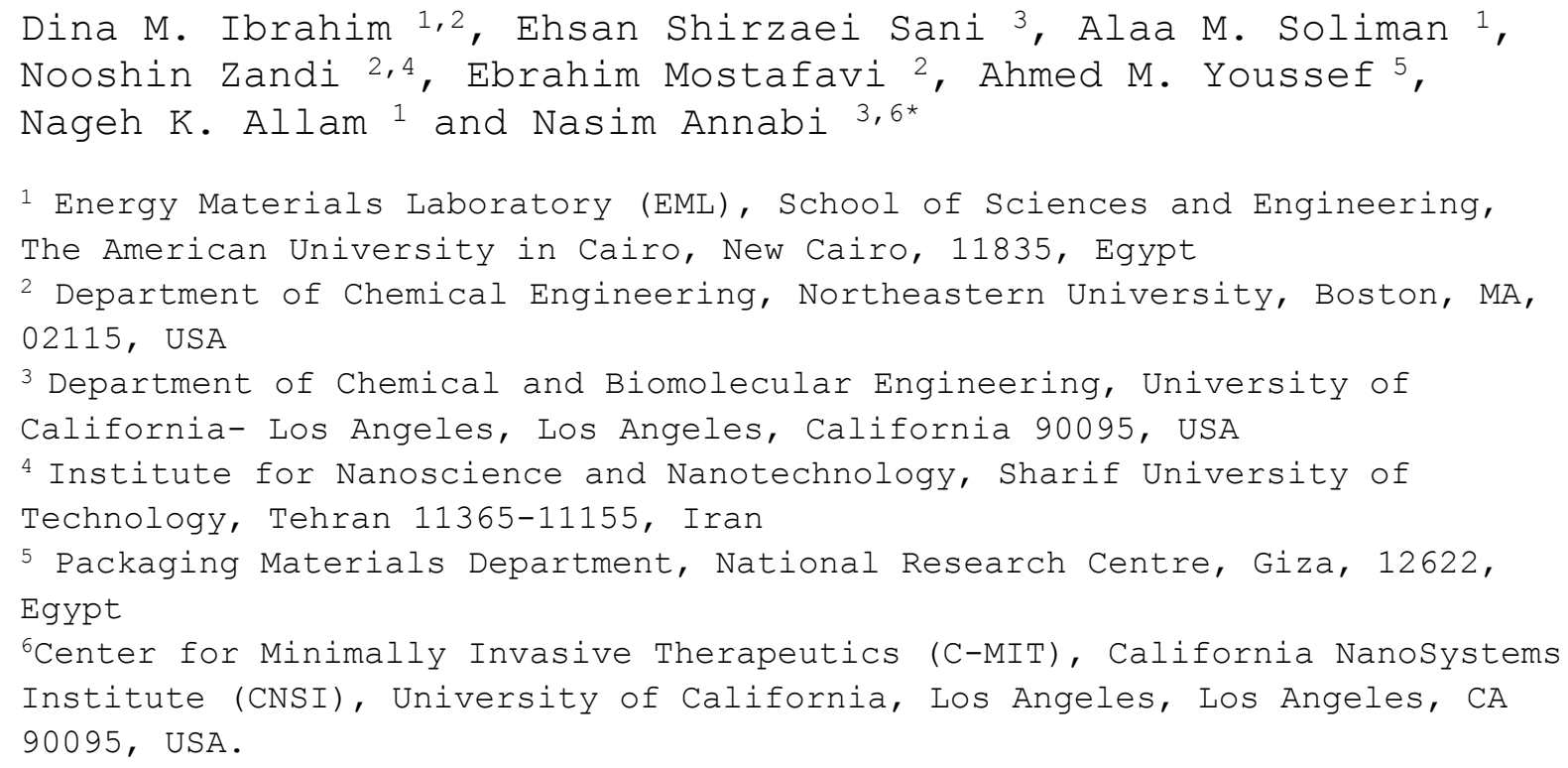

*Corresponding Author: Nasim Annabi: nannabi@UCLA.edu 
Table S1. The ratio of ${ }^{1} \mathrm{H}$ NMR between PGS and PEG was determined by integrating the methylene peaks within PEG and sebacic acid which was closely associated with the theoretical ratio used in the experimental reaction showing that the copolymer synthesis process was well controlled.

\begin{tabular}{lcc}
\hline Polymer & $\begin{array}{c}\text { Theoretical \%PEG in } \\
\text { copolymer }\end{array}$ & $\begin{array}{c}\text { Calculated \%PEG in } \\
\text { copolymer }\end{array}$ \\
\hline PGS & - & - \\
\hline PGS-co-10PEG & 10 & 12 \\
\hline PGS-co-20PEG & 20 & 21 \\
\hline PGS-co-40PEG & 40 & 39 \\
\hline
\end{tabular}

a)

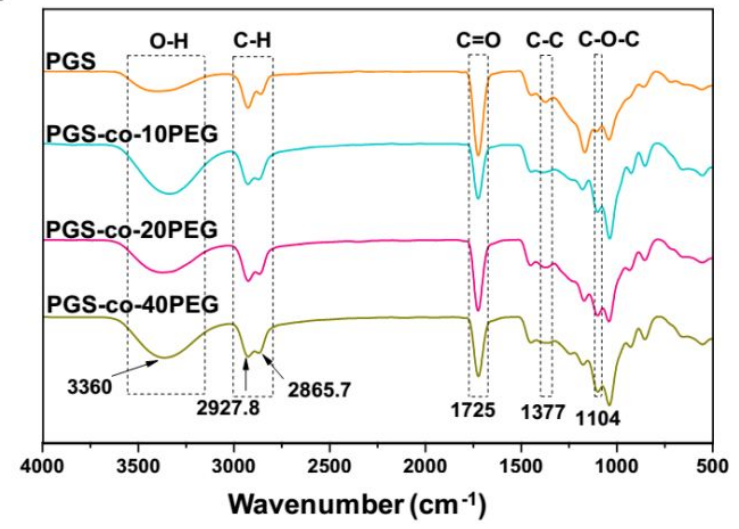

b)

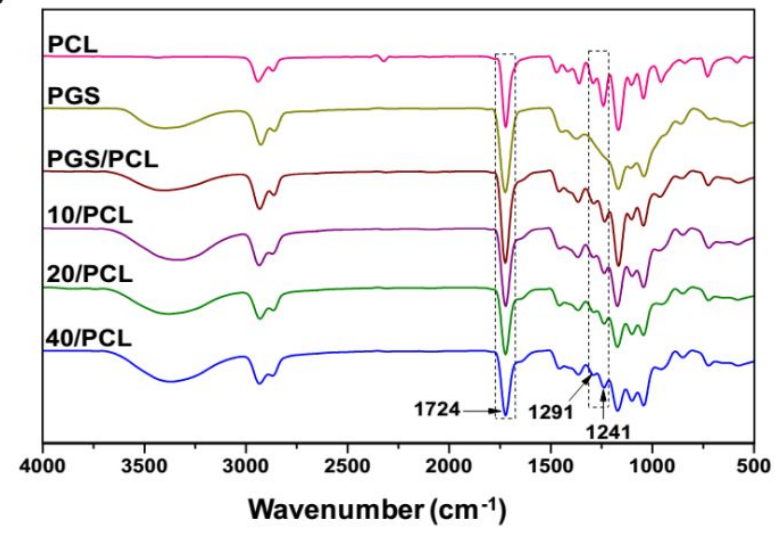

Figure S1. (a) FTIR spectra of PGS, PGS-co-10PEG, PGS-co-20PEG, PGS-co-40PEG. (b) FTIR spectra of PCL, PGS, and electrospun scaffolds of PGS/PCL, 10/PCL, 20/PCL, 40/PCL 
Table S2. Summary for fiber diameters and pore sizes of scaffolds and nanocomposites of different formulation.

\begin{tabular}{lccc}
\hline \multicolumn{1}{c}{ Scaffolds } & Sample code & Fiber diameter & Pore size \\
\hline PGS/PCL & PGS/PCL & $3.3 \pm 0.5 \mu \mathrm{m}$ & $3.8 \pm 1.7 \mu \mathrm{m}$ \\
PGS-co-10PEG/PCL & $10 / \mathrm{PCL}$ & $2.6 \pm 0.4 \mu \mathrm{m}$ & $2.7 \pm 1.3 \mu \mathrm{m}$ \\
PGS-co-20PEG/PCL & 20/PCL & $2.4 \pm 0.3 \mu \mathrm{m}$ & $2.9 \pm 1.1 \mu \mathrm{m}$ \\
\hline PGS-co-40PEG/PCL & 40/PCL & $2.6 \pm 0.5 \mu \mathrm{m}$ & $2.2 \pm 1.2 \mu \mathrm{m}$ \\
PGS-co-40PEG/PCL/1\%Laponite & 40/PCL/1LA & $1.5 \pm 0.2 \mu \mathrm{m}$ & $2.3 \pm 0.9 \mu \mathrm{m}$ \\
PGS-co-40PEG/PCL/5\%Laponite & 40/PCL/5LA & $1.3 \pm 0.3 \mu \mathrm{m}$ & $2.5 \pm 0.9 \mu \mathrm{m}$ \\
\hline PGS-c0-40PEG/PCL/10\%Laponite & 40/PCL/10LA & $0.8 \pm 0.2 \mu \mathrm{m}$ & $2.1 \pm 0.7 \mu \mathrm{m}$ \\
\hline
\end{tabular}
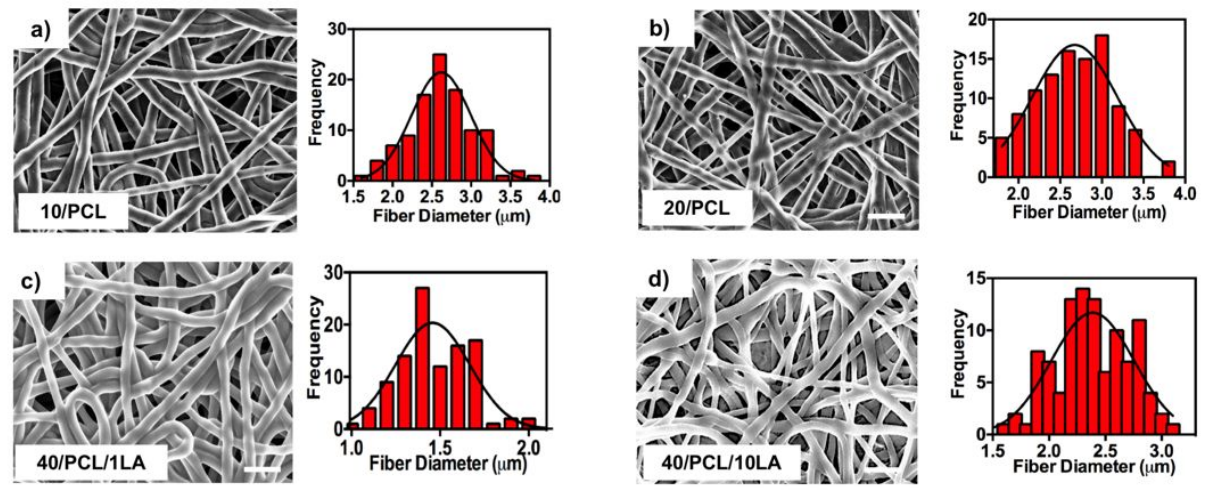

Figure S2. Representative SEM images for (a) 10/PCL, (b) 20/PCL, (c) 40/PCL/1LA and (d) 40/PCL/10LA, scale bar $=10 \mu \mathrm{m}$. 
a)

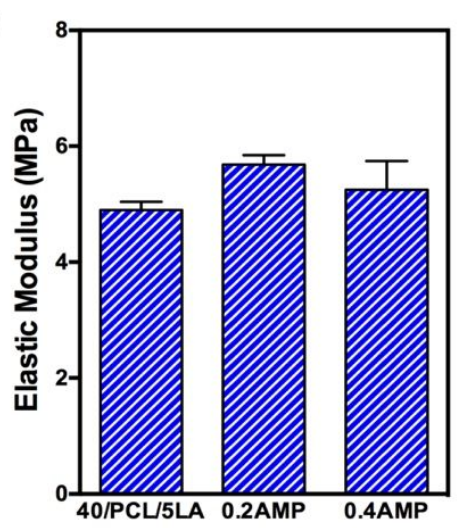

b)

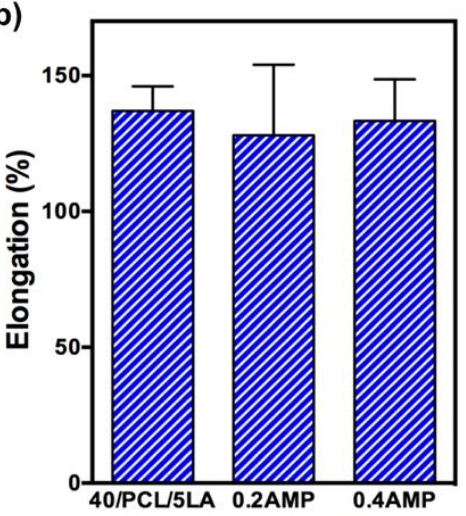

c)

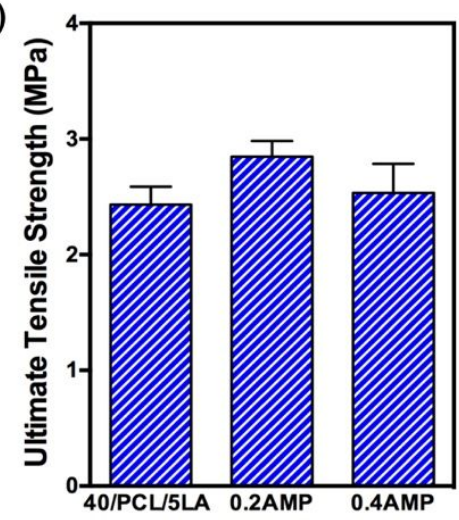

d)

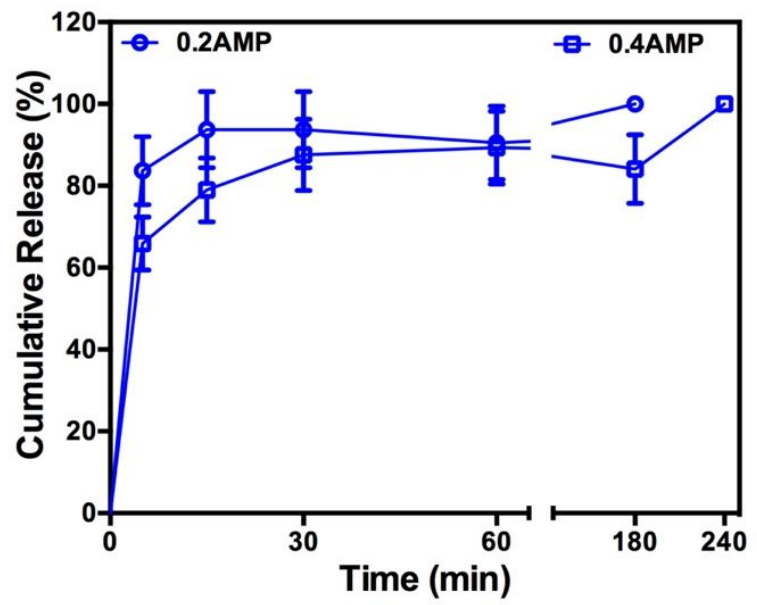

Figure S3. AMPs effect on the mechanical properties of the nanocomposites and AMPs release profile, (a) elastic modulus, (b) elongation and (c) ultimate tensile strength of nanocomposites with different AMP concentration. (d) release profile of AMP loaded nanocomposites. $(n=3)$ 


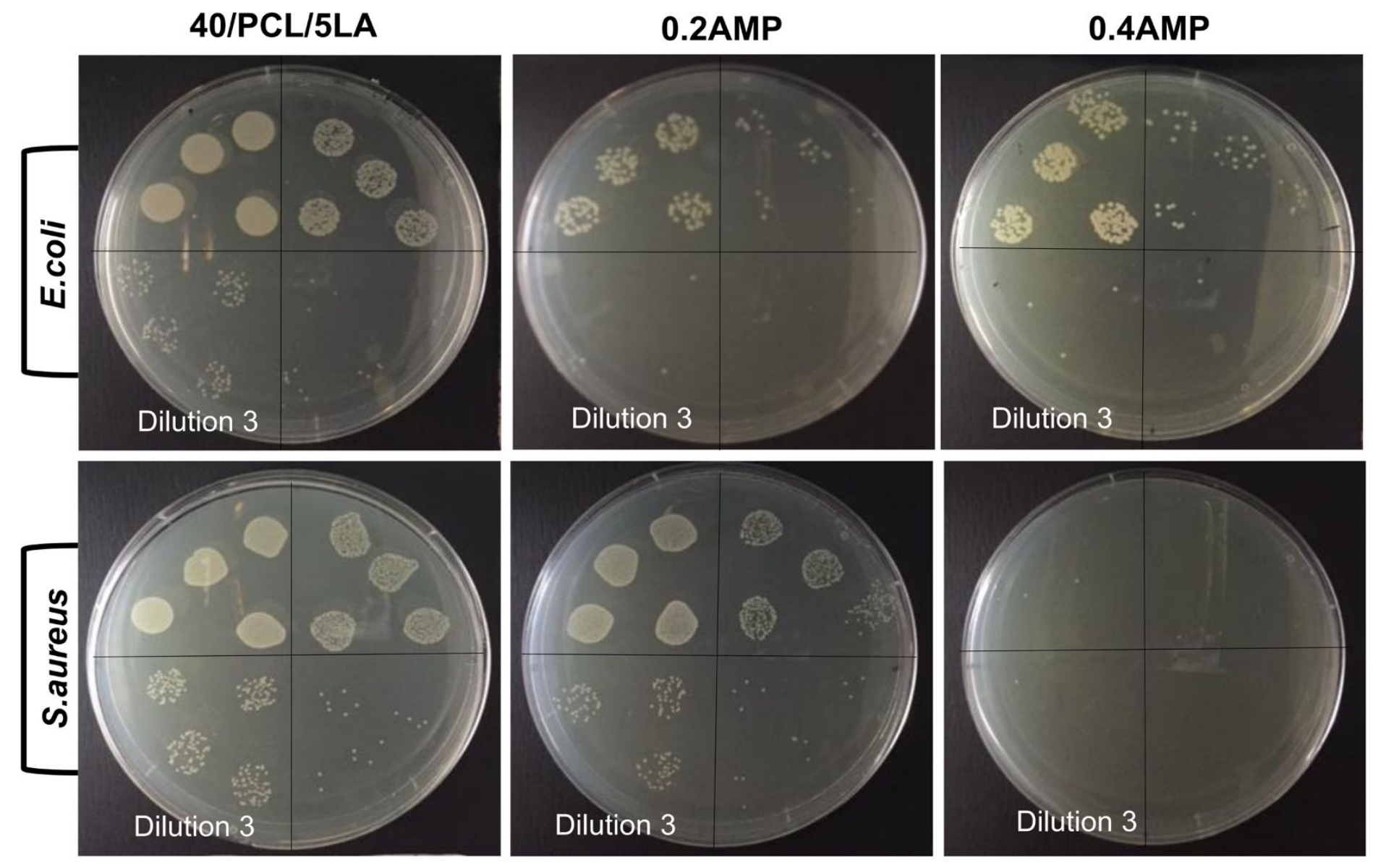

Figure S4. Bacterial colonies growing on tryptic soy agar after 12 hours incubation with 40/PCL/5LA and nanocomposites loaded with different AMPs concentration. 
Table S3. Primer sequence used in RT-PCR

\begin{tabular}{|c|c|c|}
\hline Primer name & orientation & $\begin{array}{l}\text { Primer sequences } \\
\text { 5' to 3' orientation }\end{array}$ \\
\hline GAPDH & $\begin{array}{l}\text { Forward } \\
\text { Reverse }\end{array}$ & $\begin{array}{l}\text { TCACCACCATGGAGAAGGC } \\
\text { GCTAAGCAGTTGGTGGTGCA }\end{array}$ \\
\hline$\beta$-actin & $\begin{array}{l}\text { Forward } \\
\text { Reverse }\end{array}$ & $\begin{array}{l}\text { CGGTTCCGATGCCCTGAGGCTCTT } \\
\text { CGTCACACTTCATGATGGAATTGA }\end{array}$ \\
\hline ALP & $\begin{array}{l}\text { Forward } \\
\text { Reverse }\end{array}$ & $\begin{array}{l}\text { GGGGACATGCAGTATGAATT } \\
\text { GGCCTGGTAGTTGTTGTGAG }\end{array}$ \\
\hline Axin 2 & $\begin{array}{l}\text { Forward } \\
\text { Reverse }\end{array}$ & $\begin{array}{l}\text { AGCCTAAAGGTCTTATGTGG } \\
\text { ATGGAATCGTCGGTCAGT }\end{array}$ \\
\hline COL1A1 & $\begin{array}{l}\text { Forward } \\
\text { Reverse }\end{array}$ & $\begin{array}{l}\text { CCTCAGGGTATTGCTGGACAAC } \\
\text { CAGAAGGACCTTGTTTGCCAGG }\end{array}$ \\
\hline RUNX2 & $\begin{array}{l}\text { Forward } \\
\text { Reverse }\end{array}$ & $\begin{array}{l}\text { CTTCATTCGCCTCACAAAC } \\
\text { GTCACTGCGCTGAAGA }\end{array}$ \\
\hline
\end{tabular}

